\title{
NF-Y is essential for expression of the proapoptotic bim gene in sympathetic neurons
}

\author{
R Hughes ${ }^{1}$, M Kristiansen ${ }^{1}$, I Lassot ${ }^{2}$, S Desagher ${ }^{2}$, R Mantovani ${ }^{3}$ and J Ham ${ }^{\star, 1}$
}

Neuronal apoptosis has a major role during development and aberrant apoptosis contributes to the pathology of certain neurological conditions. Studies with nerve growth factor (NGF)-dependent sympathetic neurons have provided important insights into the molecular mechanisms of neuronal apoptosis and the signalling pathways that regulate the cell death programme in neurons. The BH3-only protein Bim is a critical mediator of apoptosis in many cell types and in sympathetic neurons is required for NGF withdrawal-induced death. However, regulation of bim expression is complex and remains incompletely understood. We report that a conserved inverted CCAAT box (ICB) in the rat bim promoter is bound by the heterotrimeric transcription factor NF-Y. Interestingly, NF-Y is required for bim promoter activity and its induction following NGF withdrawal. We demonstrate that NF-Y activity is essential for endogenous Bim expression and contributes to NGF withdrawalinduced death. Furthermore, we find that the transcriptional coactivators CBP and $\mathrm{p300}$ interact with NF-Y and FOXO3a and bind to this region of the bim promoter. The amount of CBP/p300 bound to bim increases after NGF deprivation and inhibition of CBP/ p300 activity reduces bim induction. Our results indicate that NF-Y cooperates with FOXO3a to recruit CBP/p300 to the bim promoter to form a stable multi-protein/DNA complex that activates bim transcription after survival factor withdrawal.

Cell Death and Differentiation (2011) 18, 937-947; doi:10.1038/cdd.2010.166; published online 17 December 2010

The intrinsic (mitochondrial) pathway of apoptosis hinges on the balance of activity between proapoptotic and antiapoptotic members of the Bcl-2 superfamily. Bim is a BH3-only Bcl-2 family protein whose proapoptotic function is critical for apoptosis via the intrinsic pathway and Bim is one of just three BH3-only members that can bind to all five of their prosurvival relatives. ${ }^{1}$ In addition, there is mounting evidence that Bim can induce mitochondrial outer membrane permeabilisation by binding to and directly activating the multidomain proapoptotic protein Bax. $^{2}$

During development, sympathetic neurons depend on target-derived nerve growth factor (NGF) for their survival, and in its absence the cells die by apoptosis, usually within 24-48 h. ${ }^{3}$ Following NGF withdrawal, bim RNA and Bim protein levels increase rapidly and peak at around $16 \mathrm{~h}$ later. ${ }^{4}$ The overexpression of $\mathrm{Bim}_{\mathrm{EL}}$ in sympathetic neurons is sufficient to induce the release of cytochrome $c$ and apoptosis in the presence of NGF and sympathetic and sensory neurons isolated from $\mathrm{bim}^{-1-}$ knockout mice are significantly protected from trophic factor withdrawal-induced death. ${ }^{4,5}$

Because Bim is a potent inducer of apoptosis in many cell types, its expression is tightly regulated. In models of neuronal cell death, in which the cells depend on NGF for survival, three transcriptional pathways have been described. Activation of the MLK-JNK-C-Jun pathway is a key event for bim upregulation in sympathetic neurons: the overexpression of a dominant negative c-Jun protein reduces the increase in bim mRNA and protein level that occurs after NGF withdrawal ${ }^{4}$ and the jun $^{A A}$ knock-in mutation, which eliminates the two major JNK phosphorylation sites in C-Jun, reduces the increase in Bim protein level after NGF withdrawal. $^{6}$ Furthermore, bim transcription is negatively regulated by $\mathrm{PI} 3-\mathrm{K}-\mathrm{Akt}$ signalling: active Akt phosphorylates FOXO3a, which is sequestered in the cytoplasm by 14-3-3 protein and following NGF withdrawal FOXO3a translocates into the nucleus of sympathetic neurons and activates bim expression via two conserved FOXO sites. ${ }^{7}$ Moreover, FOXO activity contributes to the NGF deprivation-induced death of sympathetic neurons. ${ }^{7}$ Additionally, bim is activated by a Cdk4-E2F-Myb pathway following NGF withdrawal in neuronally differentiated PC12 cells and this requires Myb-binding sites in the bim promoter. ${ }^{8}$ Previous studies have therefore identified important transcriptional mechanisms by which bim is regulated following growth factor withdrawal, however, nothing is currently known about the bim core promoter.

The DNA region that contains the core promoter is critical for the recruitment and assembly of the RNA polymerase II transcription initiation complex. ${ }^{9}$ It is important to fully understand the bim core promoter architecture, as the regulatory pathways that activate or repress bim transcription must ultimately act upon this region. Here, we use NGF-dependent sympathetic neurons to investigate how the DNA-binding

\footnotetext{
${ }^{1}$ Molecular Haematology and Cancer Biology Unit, Institute of Child Health, University College London, London, UK; ${ }^{2}$ Institut de Génétique Moléculaire de Montpellier, Université Montpellier 1, Université Montpellier 2, Montpellier, France and ${ }^{3}$ Dipartimento di Scienze Biomolecolari e Biotecnologie, Università degli Studi di Milano, Milan, Italy

${ }^{*}$ Corresponding author: J Ham, Molecular Haematology and Cancer Biology Unit, Institute of Child Health, University College London, 30 Guilford Street, London WC1N 1EH, UK. Tel: + 44207905 2294; Fax: + 44207813 2339; E-mail: J.Ham@ich.ucl.ac.uk

Keywords: apoptosis; sympathetic neuron; Bim; NF-Y; CBP/p300

Abbreviations: NGF, nerve growth factor; ICB, inverted CCAAT box; EMSA, electrophoretic mobility shift assay; ChIP, chromatin immunoprecipitation; GTP C1, GTP cyclohydrolase I; co-IP, co-immunoprecipitation; ss, supershift; gp IgG, guinea pig IgG; TRD, Texas red dextran; CGN, cerebellar granule neuron

Received 12.5.10; revised 18.10.10; accepted 12.11.10; Edited by L Greene; published online 17.12.10
} 
transcription factor NF-Y and the coactivators CBP and p300 contribute to bim promoter function and activation following NGF withdrawal. Our results suggest a model in which NF-Y and $\mathrm{CBP} / \mathrm{p} 300$, together with $\mathrm{FOXO} 3 \mathrm{a}$, are part of a multiprotein complex that is regulated by NGF.

\section{Results}

NF-Y binds to an inverted CCAAT box in the bim proximal promoter. Since bim has a TATA-less promoter we were interested to establish what factor(s) control its basal promoter function and how these regulate bim expression following NGF deprivation in sympathetic neurons. Using ConSite DNA analysis software ${ }^{10}$ (http:// www.phylofoot.org/) we identified a conserved inverted CCAAT box (ICB) ${ }^{11}$ that is located 29 or 54 bp upstream of the major transcriptional start site in rat and human bim, respectively (Figure 1). The major CCAAT box-binding protein is NF-Y, a heterotrimer formed by the interaction of three subunits, NF-YA, B and C. ${ }^{11}$

To investigate whether NF-Y can bind to the ICB in the bim promoter, we performed some electrophoretic mobility shift assays (EMSAs). An oligo containing a previously identified CCAAT box in the rat GTP cyclohydrolase I (GTP C1) gene ${ }^{12}$ was used as a positive control (Figure 2a, lanes 1-4). Initially EMSA experiments were performed with nuclear extracts from neuronally differentiated PC6-3 cells, a PC12 subline (Figure 2a). The nuclear extracts contained proteins that bound the GTP C1 CCAAT box (lanes 1-4) and this binding (marked NF-Y complex) was abolished by point mutations in the CCAAT box consensus (lanes 5 and 6). NF-YA is the regulatory subunit and is responsible for sequence specific DNA binding. ${ }^{13}$ Therefore, antibodies specific to the NF-YA subunit or to c-Jun (as a negative control) were used for supershift assays. The c-Jun antibody did not alter the binding pattern (lane 4), whereas the NF-Y antibody supershifted the entire protein complex (marked ss) (lane 3 ). The binding of NF-Y to the bim ICB (lane 8) was similar to the binding of NF-Y to the GTP C1 probe (lane 2), and the NF-Y complex behaved

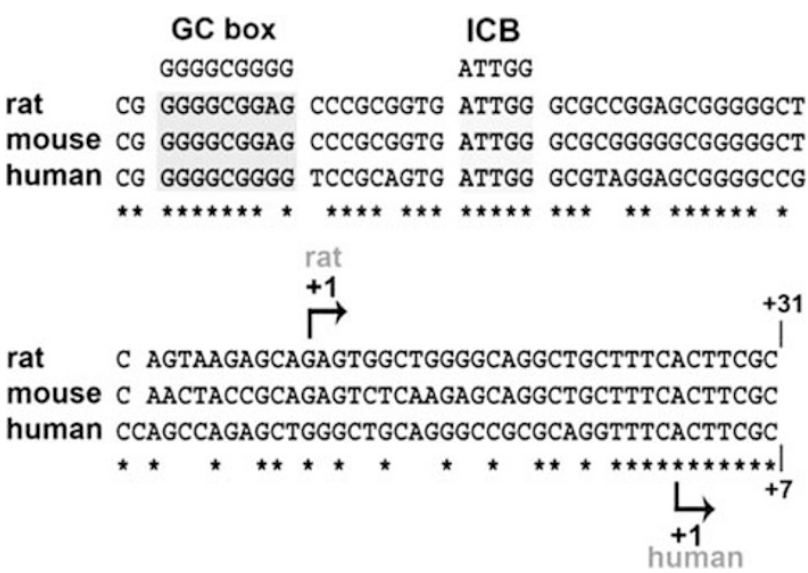

Figure 1 Alignment of the proximal promoter sequences for the rat, mouse and human bim genes. The ICB is located 29-bp or 54-bp upstream of the transcriptional start site in rat and human, respectively. The asterisks indicate bases that are conserved across all three species in an identical fashion when antibodies against NF-Y were added (lanes 3 and 9). We also performed EMSA experiments with whole cell extracts prepared from sympathetic neurons (Figure 2b). Extracts from sympathetic neurons maintained in the presence of NGF (lane 2) reproduced the binding pattern that was observed with extracts from differentiated PC6-3 cells in Figure $2 \mathrm{a}$, and binding did not change following NGF withdrawal (lane 3). The NF-Y complex was supershifted with the NF-YA antibody (lanes 4 and 5) but not a negative control antibody (Fra-2; lanes 6,7) and binding was abolished by mutations in the ICB (lanes 9 and 10).

To confirm that NF-Y can bind to the endogenous bim promoter, we carried out chromatin immunoprecipitation (ChIP) assays using the NF-YA antibody or with an antibody against $M y o D$ as a negative control (Figures $2 c$ and $d$ ). Neuronally differentiated PC6-3 cells were maintained in the presence or absence of NGF for $16 \mathrm{~h}$. The binding of NF-Y to the ICB in the bim promoter was detected by $\mathrm{PCR}$, using primers that amplify the region that contains the ICB. The negative control antibody to MyoD immunoprecipitated background levels of bim promoter chromatin, however this was significantly enriched by the antibody against NF-YA in cells maintained in the presence of NGF and following NGF withdrawal (Figures $2 \mathrm{c}$ and d). Therefore, $N F-Y$ is bound to the ICB in the rat bim promoter in the presence and absence of NGF, with no significant change in the amount of NF-Y bound to the promoter following withdrawal of NGF.

The ICB is critical for bim promoter function and contributes to the activation of bim transcription following NGF withdrawal. A bim-LUC reporter construct is significantly activated after NGF withdrawal in microinjected sympathetic neurons. ${ }^{7,14}$ To determine whether the ICB is important for bim promoter activity, the point mutations that abolished NF-Y binding (Figures $2 a$ and $b$ ) were introduced into the ATTGG pentamer within the bim-LUC construct (Figure 3a). The bim-LUC or bim-LUC CCAAT (-) constructs were then microinjected into sympathetic neurons and luciferase activity was determined following $16 \mathrm{~h}$ in the presence or absence of NGF. Mutation of the ICB resulted in an $80 \%$ decrease in basal promoter activity (Figure $3 b$ ). Following NGF withdrawal the bim-LUC reporter was activated significantly as previously reported. ${ }^{7,14}$ The basal levels of the two constructs, in the presence of NGF, were then set to one and the induction factors of the constructs compared (Figure 3c). Mutation of the ICB significantly decreased the fold induction of the bim promoter following NGF withdrawal, from $2.37 \pm 0.19$ to $1.50 \pm 0.13$.

NF-Y activity is required for Bim expression and contributes to NGF withdrawal-induced death. To establish whether NF-Y activity is required for bim promoter function, sympathetic neurons were microinjected with the YA13 m29 expression vector along with guinea pig IgG (gp $\operatorname{lgG}$ ) as a marker (Figure 4). YA13 m29 is a dominant negative mutant of the NF-YA subunit. ${ }^{15}$ It can bind to the other NF-Y subunits but not to DNA and thus acts by forming inactive NF-Y trimers. The YA13 m29 construct was microinjected into sympathetic neurons and after $24 \mathrm{~h}$ the 
a

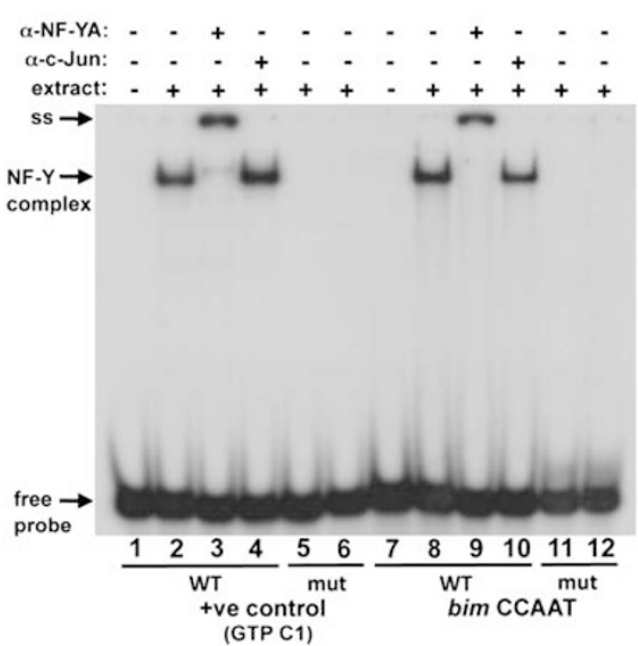

C

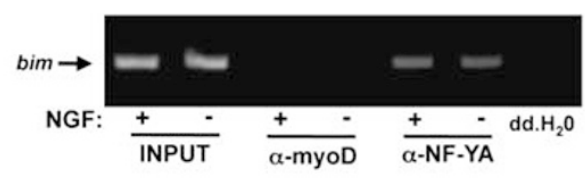

b

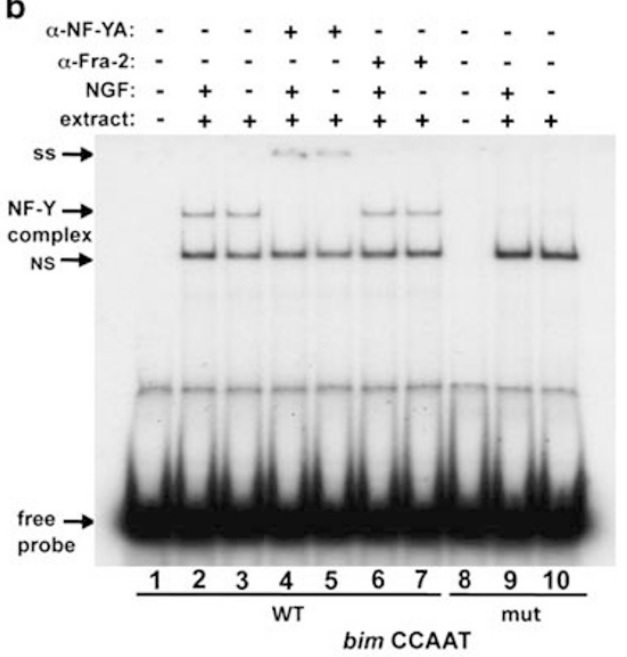

d

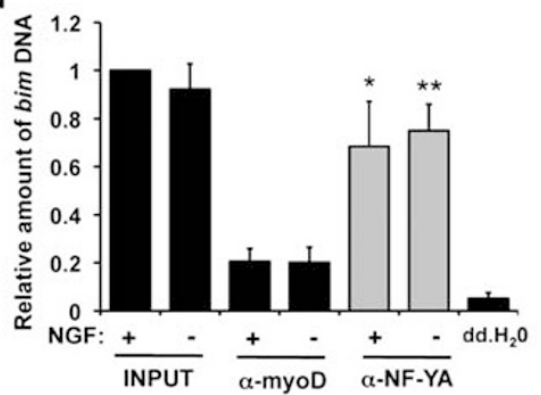

Figure 2 NF-Y binds to the bim ICB in the presence of NGF and following NGF withdrawal. (a) EMSA comparing bim CCAAT probes to a positive control probe (for rat GTP C1), using nuclear extracts from PC6-3 cells differentiated in the presence of NGF for 7 days. An NF-YA antibody (H-209) was used to supershift the NF-Y/CCAAT box complex and a c-Jun antibody (H-79) was used as a negative control. (b) EMSA with bim CCAAT probes and whole cell extracts from sympathetic neurons maintained in the presence of NGF ( + NGF) or withdrawn from NGF (-NGF) for $16 \mathrm{~h}$. An NF-YA antibody (H-209) was used to supershift the NF-Y/CCAAT box complex and a Fra-2 (L-15) antibody was used as a negative control. NS indicates a non-specific band. Representative images of several experiments are shown in each case. (c) PC6-3 cells were differentiated into a neuronal-like phenotype and then either maintained in the presence of NGF ( + NGF) or withdrawn from NGF (-NGF) for $16 \mathrm{~h}$. ChIPs were performed using an NF-YA antibody (H-209), or a MyoD antibody (M-318) as a negative control. The equivalent of $1 \%$ of the + NGF or - NGF chromatin used in each ChIP assay was also run on each gel (input) and PCR was also carried out with $\mathrm{ddH}_{2} \mathrm{O}$ as a no-template negative control. ChIP samples were analysed by semi-quantitative PCR using primers that flank the bim ICB and a representative image is shown. (d) PCR was quantitated at 25 cycles and the average amount of bim promoter DNA, precipitated by each antibody, was calculated. The data are presented as the mean \pm S.E., $n=4$. There is a significant increase in the amount of bim promoter DNA precipitated by the NF-YA antibody in both $+\operatorname{NGF}(P=0.03)$ and $-\operatorname{NGF}(P=0.009)$ conditions, compared with the negative control antibody $\left({ }^{\star *} P<0.01,{ }^{\star} P<0.05\right)$

cells were stained with an anti-NF-YA antibody. NF-YA immunostaining was considerably brighter in the nuclei of injected cells (Figure 4a) and over $90 \%$ of the injected neurons expressed high levels of NF-YA. Sympathetic neurons were then co-microinjected with YA13 m29, or the empty vector pSG5, along with the bim-LUC construct (Figure 4b). Expression of YA13 m29 completely inhibited the induction of bim-LUC following NGF withdrawal and also caused a significant decrease in the basal level of bim-LUC.

We then studied the effect of YA13 m29 on endogenous Bim protein levels (Figures $4 \mathrm{C}$ and $\mathrm{d}$ ). Sympathetic neurons were microinjected with the YA13 m29 construct, or pSG5, and then cultured $\pm N G F$ for $16 \mathrm{~h}$, after which time the cells were fixed and stained with an anti-Bim antibody. Bim is present in the cytoplasm at low levels in the presence of NGF, but strongly increases in level following NGF withdrawal (Figure 4c). Following NGF deprivation, almost $60 \%$ of the cells injected with pSG5 expressed high Bim levels
(Figure 4d). However, when the cells were injected with the YA13 m29 construct the percentage of cells expressing high levels of Bim was significantly reduced, to $10 \%$ (Figure $4 \mathrm{~d}$ ).

To investigate the role of NF-Y in NGF withdrawal-induced death, sympathetic neurons were microinjected with the YA13 m29 construct, or pSG5, together with Texas red dextran (TRD) as a marker. The neurons were then maintained in the presence or absence of NGF and the number of viable injected cells was counted at $0,24,48$ and $72 \mathrm{~h}$. Viable neurons were morphologically normal and retained TRD in the nucleus (Figure 5a). At $72 \mathrm{~h}$ following NGF withdrawal, the number of viable cells injected with the pSG5 control was below $20 \%$ (Figure $5 \mathrm{~b}$ ), whereas cells injected with YA13 m29 were partially protected from cell death (39\% were viable) (Figure 5b). The injected neurons not protected by YA13 m29 died by apoptosis following NGF withdrawal (Supplementary Figure S1). These results indicate that NF-Y activity is necessary for cell death in NGF-deprived sympathetic neurons. 
a
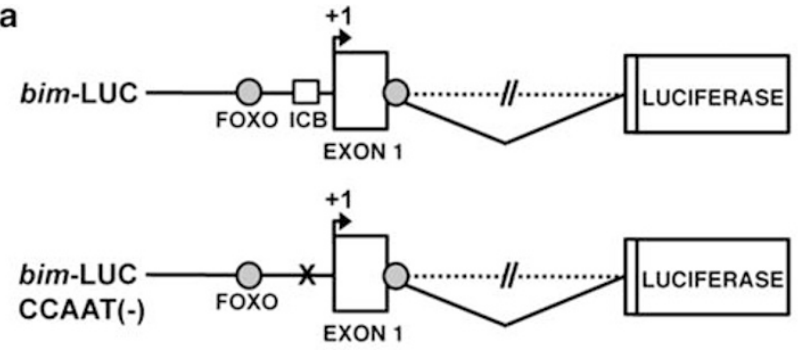

b

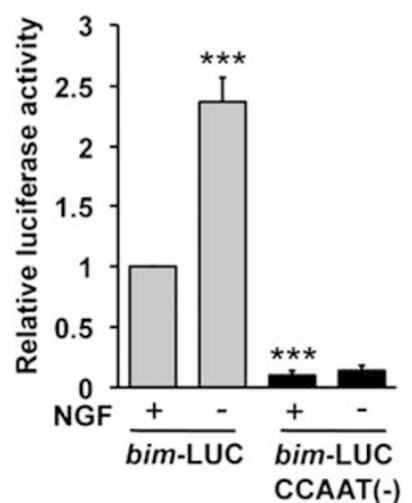

c

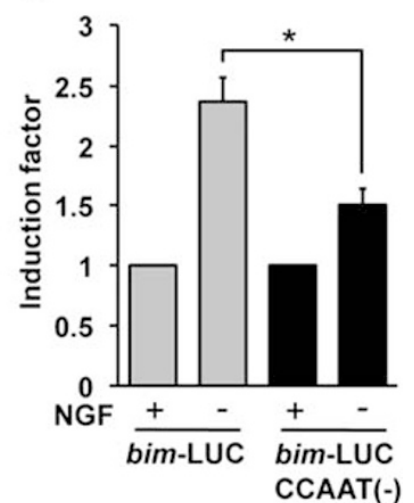

Figure 3 The ICB is critical for basal promoter function and contributes to the induction of bim transcription following NGF withdrawal. (a) Structure of the bimLUC and bim-LUC CCAAT (-) reporter constructs. Bim-LUC contains $2.5 \mathrm{~kb}$ of the rat bim promoter, the non-coding exon 1 and the $2.5 \mathrm{~kb}$ intron upstream of the firefly luciferase gene. The location of the conserved FOXO-binding sites and the ICB are shown. The bim-LUC CCAAT (-) construct contains four point mutations within the ICB consensus that were introduced by site-directed mutagenesis. (b) Sympathetic neurons were microinjected with bim-LUC or bim-LUC CCAAT $(-)$ (both at $10 \mathrm{ng} / \mu \mathrm{l}$ ) along with $\mathrm{pRL}-\mathrm{TK}$ at $5 \mathrm{ng} / \mu \mathrm{l}$ (to control for injection efficiency). The cells were maintained in medium containing NGF ( +NGF) or withdrawn from NGF (-NGF) for $16 \mathrm{~h}$, after which time luciferase activity was measured. The data are presented as the mean \pm S.E., $n=5$. Bim-LUC is activated significantly following NGF withdrawal $(P=0.0003)$. Mutation of the ICB significantly decreases the basal promoter level of bim-LUC $(P=0.0009)$. (c) The basal levels of bim-LUC and bim-LUC CCAAT (-) were normalised to one and the induction factors of the two constructs were compared. Mutation of the ICB significantly decreases the induction of bim-LUC following NGF withdrawal $(P=0.018) .\left({ }^{\star \star \star} P<0.001,{ }^{*} P<0.05\right)$

CBP and p300 are important for activation of the bim promoter following NGF withdrawal. The ICB and NF-Y activity are necessary for bim promoter activation following NGF withdrawal, but the mechanism by which NF-Y functions has yet to be elucidated, since NF-Y is bound to the ICB in both the presence and absence of NGF. CBP and p300 are two distinct but highly homologous transcriptional coactivators. They can activate the transcription of a multitude of target genes and can interact with over 350 viral and mammalian proteins ${ }^{16}$ including C-Jun, FOXO3a, Myb and NF-Y, which activate bim transcription in sympathetic neurons. ${ }^{4,7,8} \mathrm{We}$ therefore investigated whether $\mathrm{CBP} / \mathrm{p} 300$ are important for bim promoter activation following NGF withdrawal. In immunocytochemistry experiments, we confirmed that CBP and p300 localise to the nucleus of sympathetic neurons, with $\sim 95 \%$ of sympathetic neurons expressing high levels of CBP and p300 in the presence and absence of NGF (Supplementary Figure S2). To study whether CBP and p300 are required for bim promoter activation, antibodies specific for CBP or p300 were co-injected into sympathetic neurons together with the bim-LUC construct (Figure 6a). The microinjection of specific antibodies can be used as a suitable alternative to conventional protein knockdown techniques in these cells. ${ }^{17-19}$ The bim-LUC construct was not significantly activated following NGF withdrawal when antibodies against CBP or p300 were co-injected, compared with the control rabbit IgG (Figure 6a). We also performed a positive control antibody co-injection experiment using a CREB reporter construct pCRE-LUC (Figure 6b), which requires CBP and p300 for its activation by protein kinase $A$ and CREB. Sympathetic neurons were co-injected with PCRE-LUC together with the CBP or p300 antibodies or rabbit IgG. Following injection the cells were treated with CPTCAMP, a membrane permeable cAMP analogue. The pCRE-LUC construct was significantly activated by CPTcAMP treatment when co-injected with IgG compared with the control construct without CRE sites, p-LUC. Importantly, injection of the CBP or p300 antibodies significantly decreased this induction.

Studies with p300 and CBP knockout mice indicate that CBP and p300 are present in cells at limiting concentrations. ${ }^{20,21}$ Therefore, overexpression of $\mathrm{p} 300$ or CBP should activate the bim promoter in the presence of NGF. Sympathetic neurons were co-microinjected with $\mathrm{pRc} / \mathrm{RSV}$-mCBP or the control empty vector $\mathrm{pBJ} 9 \Omega$, or $\mathrm{CMVp300}$ or the control empty vector pcDNA3.1, together with the bim-LUC reporter construct (Figure 6c). Bim-LUC was significantly activated by overexpression of either CBP or p300. Interestingly, overexpression of p300 did not activate bim-LUC CCAAT (-) (Figure 6d) suggesting that the ICB must be intact for activation of the bim promoter by p300.

The amount of CBP/p300 bound to the bim promoter is regulated by NGF withdrawal. To confirm that p300 and CBP can bind to the endogenous bim promoter, we performed ChIP assays using differentiated PC6-3 cells and the p300 and CBP antibodies, along with antibodies against MyoD and Bim as negative controls (Figures $7 a$ and $b$ ). The binding of $\mathrm{p} 300$ or CBP to the bim core promoter was studied by PCR using the primers that were previously used to study the binding of NF-Y to the ICB. In the presence of NGF, there was some binding of $\mathrm{p} 300$ and $\mathrm{CBP}$ to the bim promoter but this was significantly enriched following NGF withdrawal (Figures $7 a$ and b). Therefore, p300 and CBP are bound to the same region of the bim promoter as NF-Y and the amount of p300 and CBP bound to the promoter increases 2.1-fold following NGF withdrawal.

CBP/p300 interact with NF-Y in the presence of NGF and following NGF withdrawal. To investigate whether NF-Y and $\mathrm{CBP} / \mathrm{p} 300$ interact in extracts from NGF-dependent cells, co-immunoprecipitation (co-IP) experiments were carried out (Figure $7 c$ and Supplementary Figure S3a). Nuclear extracts were prepared from differentiated PC6-3 cells cultured $\pm N G F$ for $16 \mathrm{~h}$. The nuclear extracts were immunoprecipitated with antibodies against p300, CBP, NF-YA or rabbit IgG. Immunoblotting was then performed using an NF-YA antibody (Figure 7c). Importantly, NF-YA was precipitated with antibodies against $\mathrm{CBP}$ and p300 but not the control rabbit IgG. In addition, the NF-Y antibody 
a

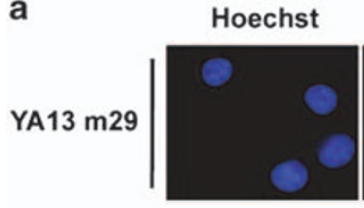

C

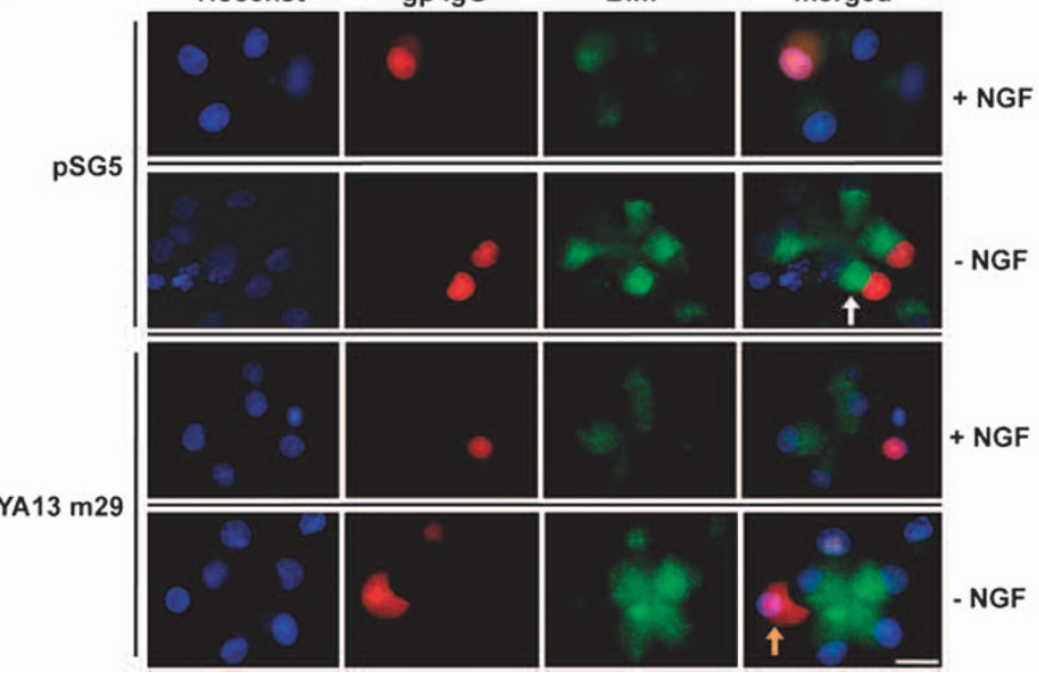

NF-YA
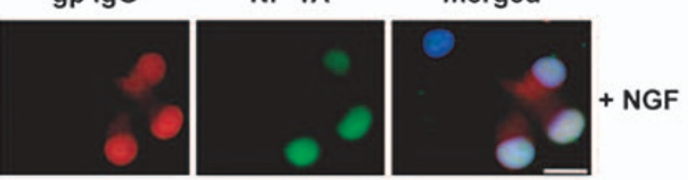

gp $\lg G$
Bim

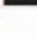


a
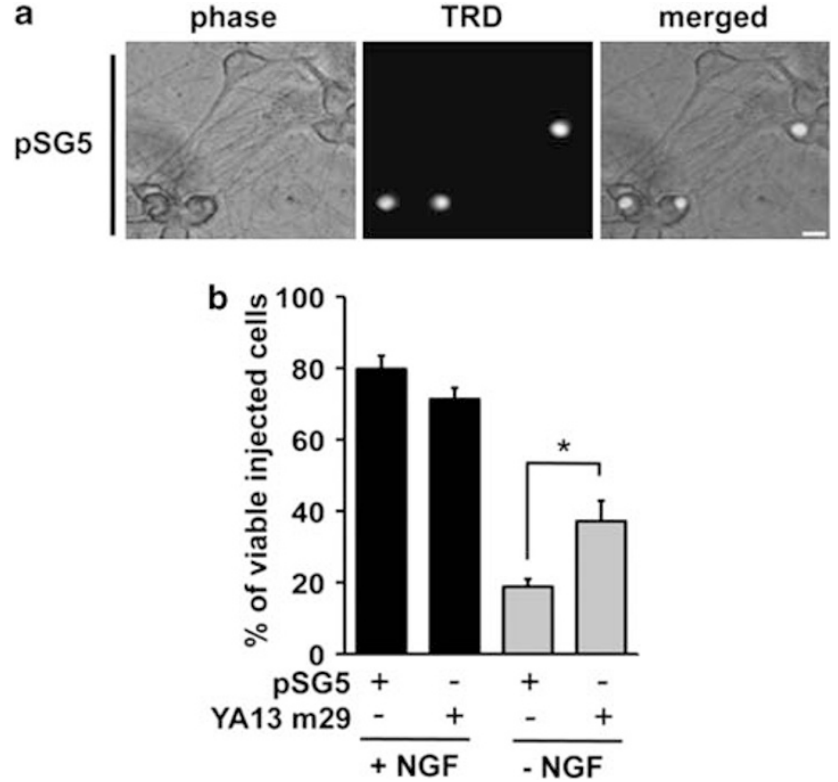

Figure 5 NF-Y activity contributes to cell death following NGF withdrawal in sympathetic neurons. Sympathetic neurons were injected with the YA13 m29 construct or the control empty vector pSG5 at $200 \mathrm{ng} / \mu \mathrm{l}$, along with TRD at $5 \mu \mathrm{g} / \mu \mathrm{l}$ as a marker for injected cells. The cells were either maintained in medium containing NGF ( + NGF) or withdrawn from NGF (-NGF) and the number of viable, injected cells was determined at $0,24,48$ and $72 \mathrm{~h}$. Viable cells were counted in a blinded manner. (a) Example images of sympathetic neurons injected with pSG5 and TRD. Neurons were considered viable if they were morphologically normal and retained TRD in their nucleus. The scale bar represents $20 \mu \mathrm{m}$. (b) The number of viable cells, injected with YA13 m29 or pSG5, at $72 \mathrm{~h}$ following NGF withdrawal. The data are presented as the mean \pm S.E., $n=4$. Microinjection of the YA13 m29 construct significantly increases the percentage of viable cells at $72 \mathrm{~h}-\mathrm{NGF}$ compared with the control pSG5 $(P=0.023)$. $\left({ }^{\star} P<0.05\right)$

(Figure 8a). We compared bim-LUC CCAAT(-) FOXO(dm) with the wild type bim-LUC in microinjection experiments with sympathetic neurons (Figure 8b). Loss of both FOXO sites, together with the ICB, significantly reduced the basal promoter level, as shown previously for bim-LUC CCAAT $(-)$. Interestingly, loss of all three sites completely abolished the induction of bim-LUC following NGF withdrawal. This indicates that the two FOXO sites are required for the residual induction that is seen with bim-LUC CCAAT (-) after NGF deprivation.

We also investigated the effect on cell survival after NGF withdrawal of inhibiting both NF-Y and FOXO activity. YA13 m29 was co-expressed with the FKH (DBD), and TRD was used as a marker. The FKH (DBD) construct expresses the DNA-binding domain (DBD) of FOXO3a, which is a specific inhibitor of FOXO transcriptional activity. ${ }^{7}$ Following injection, the neurons were withdrawn from NGF for $72 \mathrm{~h}$ and the number of viable injected cells was determined (Figure 8c). In accordance with Figure $5 \mathrm{~b}$, at $72 \mathrm{~h}$ following NGF withdrawal, the number of viable cells injected with the control (pSG5 + pcDNA.1) was $\sim 15 \%$, whereas cells that were injected with YA13 m29 were partially protected from cell death $(\sim 40 \%$ of cells were viable at $72 \mathrm{~h}-\mathrm{NGF})$. As demonstrated previously by Gilley et al., ${ }^{7}$ neurons injected with the FKH (DBD) construct were better protected $(58 \%$ of cells were viable at $72 \mathrm{~h}-\mathrm{NGF})$. Co-expression of both YA13 a

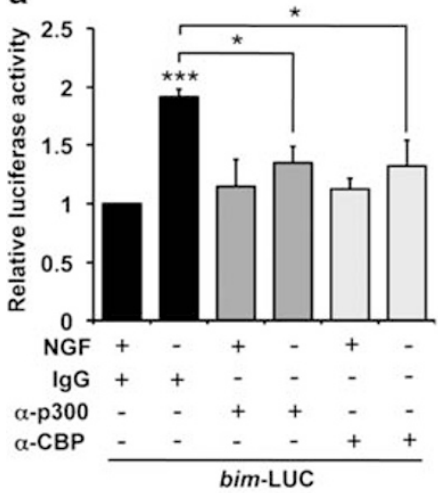

b

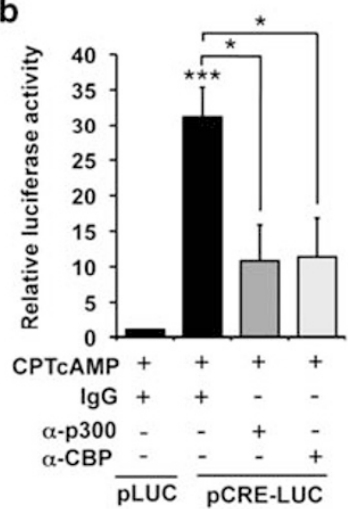

C

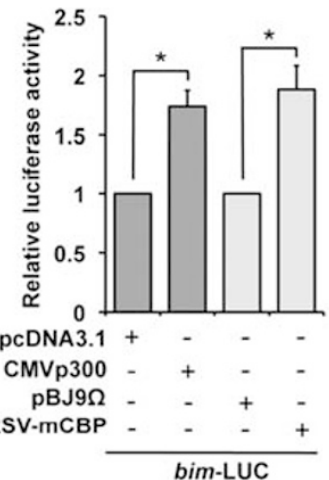

d

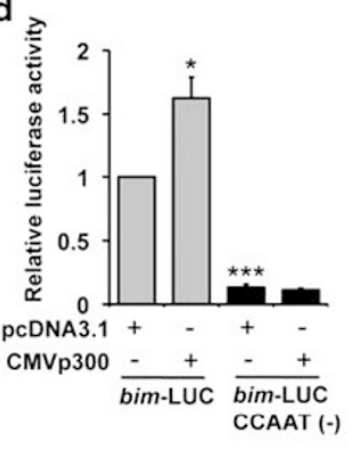

Figure $6 \mathrm{CBP}$ and $\mathrm{p} 300$ are important for activation of the bim promoter in sympathetic neurons. (a) Co-microinjection of antibodies specific to p300 or CBP with bim-LUC. Sympathetic neurons were microinjected with bim-LUC at $10 \mathrm{ng} / \mu \mathrm{l}$ and pRL-TK at $5 \mathrm{ng} / \mu \mathrm{l}$, together with the p300 (C-20:585) or CBP (C-20:583) antibodies, or rabbit lgG as a control, each at $1 \mu \mathrm{g} / \mu \mathrm{l}$. The cells were maintained in medium containing NGF ( + NGF) or withdrawn from NGF (-NGF) for $16 \mathrm{~h}$, after which time luciferase activity was measured. The data are presented as the mean \pm S.E., $n=6$. Bim-LUC is activated significantly following NGF withdrawal when co-injected with rabbit $\lg G(P=0.0001)$. Bim-LUC is not activated significantly when co-microinjected with the p300 and CBP antibodies. There is a significant decrease in the induction of bim-LUC following NGF withdrawal when co-injected with the p300 antibody $(P=0.034)$ and the CBP antibody $(P=0.013)$ compared with the control rabbit IgG. (b) Sympathetic neurons were microinjected with pCRELUC or pLUC (as a control), each at $20 \mathrm{ng} / \mu \mathrm{l}$, and pRL-TK at $5 \mathrm{ng} / \mu \mathrm{l}$, together with the p300 (C-20:585) or CBP (C-20:583) antibodies or rabbit lgG, each at $1 \mu \mathrm{g} / \mu \mathrm{l}$. After injection, the cells were treated with $500 \mu \mathrm{M}$ CPTcAMP for $16 \mathrm{~h}$, after which time luciferase activity was measured. The data are presented as the mean \pm S.E., $n=5$. The pCRE-LUC is activated significantly following addition of CPTCAMP, in comparison with pLUC $(P=0.0002)$. There is a significant decrease in the activation of PCRE-LUC following addition of CPTCAMP when co-injected with the p300 antibody $(P=0.019)$ and the CBP antibody $(P=0.028)$ compared with the control rabbit $\mathrm{IgG}$. (c) Co-microinjection of the p300 expression vector, CMVp300, or the CBP expression vector, pRc/RSV-mCBP, with bim-LUC. Sympathetic neurons were microinjected with bim-LUC at $10 \mathrm{ng} / \mu \mathrm{l}$ and $\mathrm{pRL}-\mathrm{TK}$ at $5 \mathrm{ng} / \mu \mathrm{l}$, along with CMVp300 or the control empty vector pcDNA3.1 at $50 \mathrm{ng} / \mu \mathrm{l}$, or $\mathrm{pRc} / \mathrm{RSV}$-mCBP or the control empty vector $\mathrm{pBJ} 9 \Omega$ at $50 \mathrm{ng} / \mu \mathrm{l}$. Following injection the cells were maintained in medium containing NGF for $16 \mathrm{~h}$, after which time luciferase activity was measured. The data are presented as the mean \pm S.E., $n=4$. Co-microinjection of CMVp300 or pRc/RSV-mCBP induces a significant activation of bim-LUC $(P=0.016$ and $P=0.049$, respectively). (d) The ICB is required for bim activation by $\mathrm{p} 300$. Sympathetic neurons were microinjected with bim-LUC or bim-LUC CCAAT (-) at $10 \mathrm{ng} / \mu \mathrm{l}$ and pRL-TK at $5 \mathrm{ng} / \mu \mathrm{l}$, along with $\mathrm{CMVp} 300$ or the control empty vector pcDNA3.1 at $50 \mathrm{ng} / \mu \mathrm{l}$. Following injection, the cells were maintained in medium containing NGF for $16 \mathrm{~h}$, after which time luciferase activity was measured. The data are presented as the mean \pm S.E., $n=4$. Co-microinjection of CMVp300 induces a significant activation of bim-LUC $(P=0.013)$. Co-microinjection of CMVp300 does not activate bim-LUC CCAAT $(-)$. $\left({ }^{* \star *} P<0.001,{ }^{*} P<0.05\right)$ 
a

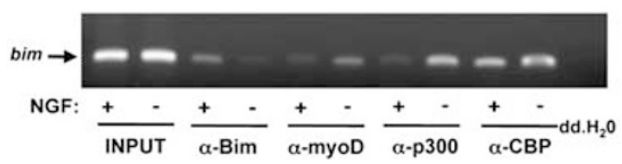

C

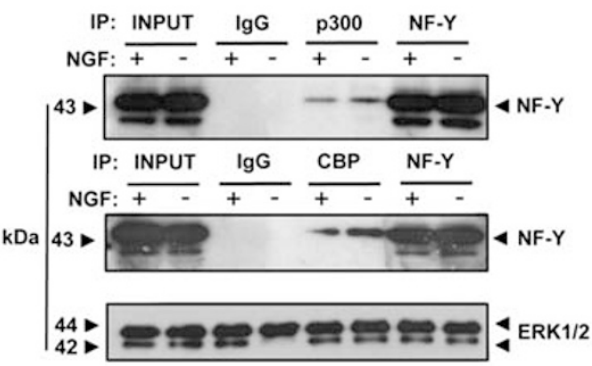

e

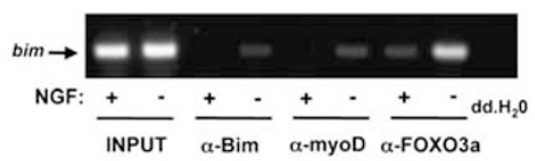

b

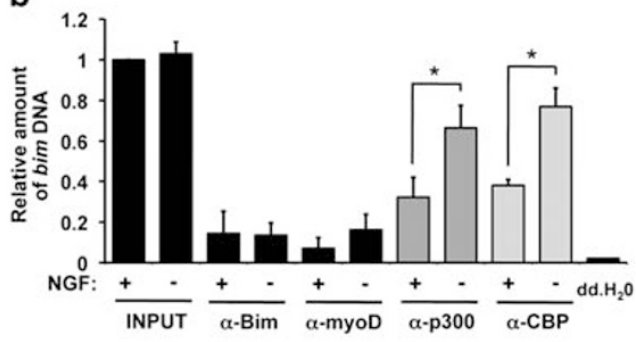

d IP: INPUT $\frac{\text { IgG }}{+-\frac{\text { p300 }}{+-} \frac{\text { FOXO3a }}{+-}}$
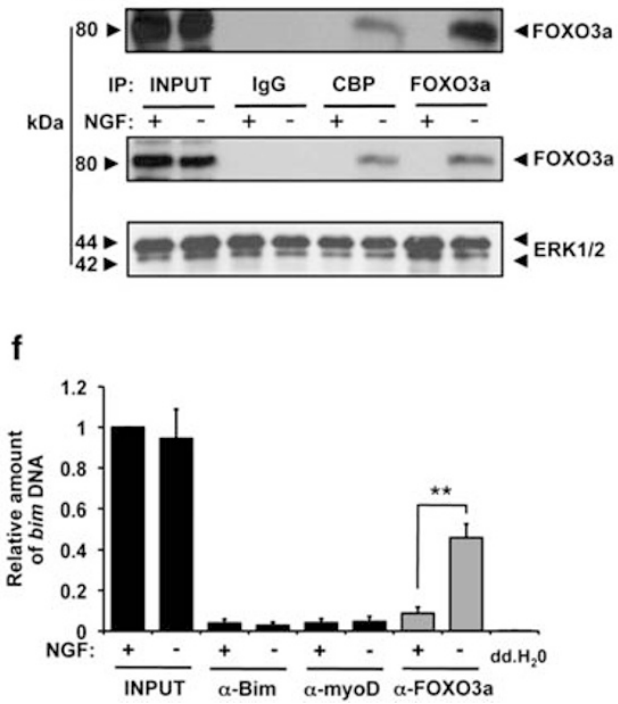

Figure 7 The amount of CBP/p300 and FOXO3a bound to the bim gene increases following NGF withdrawal and CBP/p300 can bind to both FOXO3a and NF-Y. (a) PC6-3 cells were differentiated into a neuronal-like phenotype and then either maintained in the presence of NGF ( + NGF) or withdrawn from NGF ( - NGF) for $16 \mathrm{~h}$. ChIP assays were performed using antibodies specific to p300 (C-20:585) or CBP (C-20:583). MyoD (M-318) and Bim (\# 2819) antibodies were used as negative controls. The equivalent of $1 \%$ of the + NGF or -NGF chromatin used in each ChIP assay was also run on each gel (input) and PCR was also carried out with ddH $\mathrm{H}_{2} \mathrm{O}$ as a no-template negative control. ChIP samples were analysed by semi-quantitative PCR and a representative image is shown. (b) PCR was quantitated at 30 cycles and the average amount of bim promoter DNA, precipitated by each antibody, was calculated. The data are presented as the mean \pm S.E., $n=3$. There is a significant increase in the amount of bim promoter DNA precipitated by the p300 $(P=0.05)$ and the $\operatorname{CBP}(P=0.014)$ antibodies following NGF withdrawal ( - NGF) compared with the + NGF control. (c) Co-immunoprecipitation of NF-Y with antibodies against p300 or CBP. Nuclear extracts were prepared from PC6-3 cells differentiated in the presence of NGF for 7 days and then either maintained in the presence of NGF ( + NGF) or withdrawn from NGF (-NGF) for $16 \mathrm{~h}$. The nuclear extracts were immunoprecipitated with antibodies against p300 (C-20:585), CBP (C-20:583), NF-YA (H-209), or rabbit IgG as a control. Immunoblots were then carried out on the precipitated samples using an NF-YA antibody. Total ERK1/2 (\# 9102) was used as a loading control. (d) Co-immunoprecipitation of FOXO3a with antibodies against p300 or CBP. Nuclear extracts (as above) were immunoprecipitated with antibodies against p300, CBP, FOXO3a (\#2497) or rabbit IgG. Immunoblots were then carried out on the precipitated samples using an antibody against p300 or CBP. Total ERK1/2 was used as a loading control. Representative images of several experiments are shown in each case. (e) FOXO3a binds to FOXO site 2 (exon 1/intron site) following NGF withdrawal. ChIPs were performed as described above, using an antibody specific to FOXO3a ( $\mathrm{H}-144$ :Sc-11351 X). ChIP samples were analysed by semi-quantitative PCR and a representative image is shown. (f) PCR was quantitated at 30 cycles and the average amount of bim promoter DNA, precipitated by each antibody, was calculated. The data are presented as the mean \pm S.E., $n=4$. There is a significant increase in the amount of bim promoter DNA precipitated by the FOXO3a $(P=0.006)$ antibody following NGF withdrawal (-NGF) compared with the + NGF control. $\left({ }^{\star \star} P<0.01,{ }^{\star} P<0.05\right)$

m29 and FKH (DBD) did not significantly increase cell survival compared with injection of the FKH (DBD) construct alone (Figure $8 \mathrm{c}$ ). This is probably because the FKH (DBD) construct alone already gives the maximum protection observed in this microinjection assay, similar to that conferred by $\mathrm{Bcl}-2$, dominant negative c-Jun or the JNK binding domain of JIP-1. ${ }^{23,24}$

\section{Discussion}

We have studied the role of a conserved inverted CCAAT box in the bim core promoter that is bound by NF-Y. This is the first bim promoter element that has been shown to be important for basal promoter function and as the bim promoter does not contain a TATA box, it is likely that the NF-Y-binding-ICB has an important role in pre-initiation complex assembly as reported for other TATA-less promoters. ${ }^{25}$ In addition, the ICB is critical for bim promoter activation following NGF withdrawal.

We used the YA13 m29 dominant negative mutant ${ }^{15,26,27}$ to establish that NF-Y activity is required for bim promoter function and expression of the endogenous Bim protein. Importantly, we also demonstrated that expression of YA13 m29 partially protects sympathetic neurons from NGF 
a

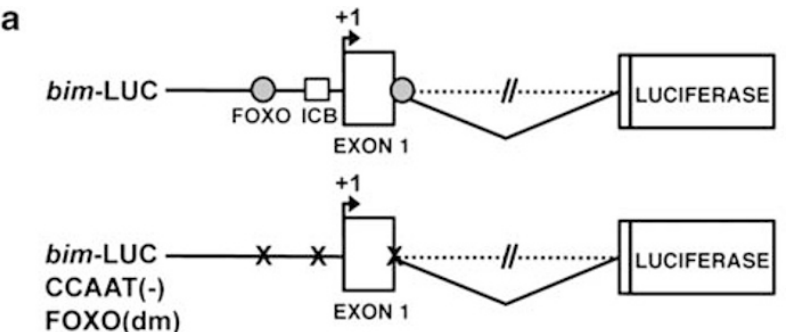

b

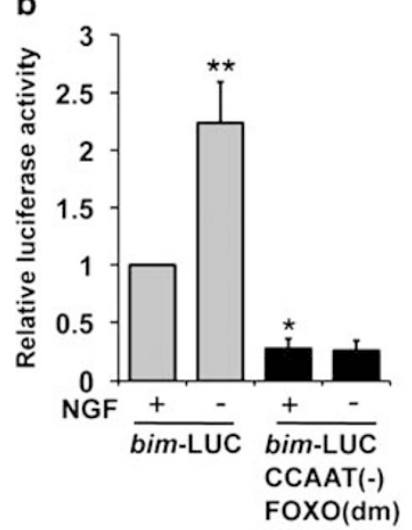

C

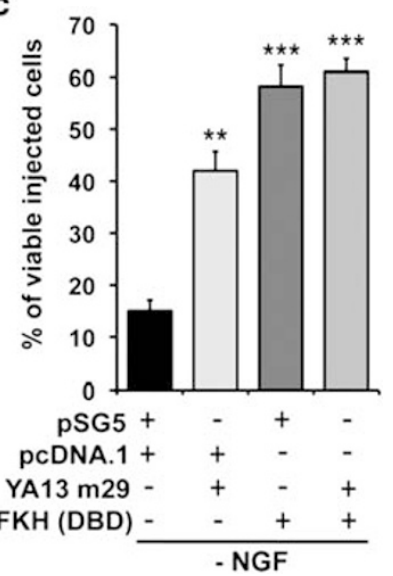

Figure 8 The ICB and FOXO sites are critical for the induction of bim transcription following NGF withdrawal. (a) Structure of the bim-LUC and bim-LUC CCAAT $(-)$ FOXO $(\mathrm{dm})$ reporter constructs. The location of the two conserved FOXO-binding sites and the ICB are shown. The bim-LUC CCAAT (-) FOXO (dm) construct contains point mutations within the ICB and FOXO consensus sequences, that were introduced by site-directed mutagenesis. (b) Sympathetic neurons were microinjected with bim-LUC or bim-LUC CCAAT (-) FOXO (dm) (both at $10 \mathrm{ng} / \mu \mathrm{l})$ along with $\mathrm{pRL}-\mathrm{TK}$ at $5 \mathrm{ng} / \mu \mathrm{l}$. The cells were maintained in medium containing NGF ( + NGF) or withdrawn from NGF (-NGF) for $16 \mathrm{~h}$, after which time luciferase activity was measured. The data are presented as the mean \pm S.E., $n=5$. Bim-LUC is activated significantly following NGF withdrawal $(P=0.01)$. Mutation of the ICB and FOXO sites significantly decreases the basal promoter level of bim-LUC $(P=0.015)$, and the induction of bim-LUC, following NGF withdrawal, is abolished. (c) NF-Y and FOXO activity contribute to cell death following NGF withdrawal in sympathetic neurons. Sympathetic neurons were injected with the YA13 m29 construct or the control empty vector pSG5 at $200 \mathrm{ng} / \mu \mathrm{l}$, together with the FKH (DBD) construct or the control empty vector $\mathrm{pcDNA} 1$ at $50 \mathrm{ng} / \mu \mathrm{l}$. TRD was added to the injection mix at $5 \mu \mathrm{g} / \mu \mathrm{l}$ as a marker for injected cells. The cells were withdrawn from NGF and the number of viable, injected cells was determined at $72 \mathrm{~h}$. Viable cells were counted in a blinded manner. The data are presented as the mean \pm S.E., $n=4$. Microinjection of the YA13 m29 construct $(P=0.002)$ or FKH(DBD) $(P=0.0007)$ or YA13 m29 + FKH(DBD) $(P=0.0002)$ significantly increases the percentage of viable cells at $72 \mathrm{~h}-\mathrm{NGF}$ compared with the control pSG5 + pcDNA1. Microinjection of FKH(DBD) together with YA13 m29 does not increase the percentage of viable cells at $72 \mathrm{~h}-\mathrm{NGF}$ compared with injection of FKH(DBD) alone. $\left({ }^{\star \star \star} P<0.001,{ }^{\star \star} P<0.01,{ }^{\star} P<0.05\right)$

withdrawal-induced death ( $\sim 40 \%$ of the cells are viable at $72 \mathrm{~h}-\mathrm{NGF}$ ). This level of protection is similar to the effect of a complete bim $^{-1-}$ knockout on neuronal survival. ${ }^{4,5}$ This partial protection is likely to be because the other $\mathrm{BH}$-only proteins that increase in level after NGF withdrawal, Puma and Dp5, can partially compensate for the loss of Bim. ${ }^{28-30}$

NF-Y can recruit the transcriptional cofactors CBP and p300 to DNA to potentiate transcription. ${ }^{31}$ As the amount of NF-Y bound to the bim promoter does not increase after NGF withdrawal, we hypothesised that the recruitment of transcriptional cofactors to the bim promoter may be regulated by NGF withdrawal. We found that co-injection of antibodies against CBP or p300 inhibits the induction of bim-LUC after NGF withdrawal and that $\mathrm{CBP}$ and $\mathrm{p} 300$ bind to the region of the bim promoter that is bound by NF-Y, and that the amount of CBP/p300 associated with bim significantly increases after NGF withdrawal.

Since CBP and p300 do not bind DNA directly, ${ }^{32}$ they must interact with proteins that are already bound to the bim promoter. We have shown that mutation of the ICB abolishes the activation of the bim-LUC reporter by p300 and that NF-Y interacts with CBP and p300 in extracts from neuronal cells. This suggests that $\mathrm{CBP} / \mathrm{p} 300$ may activate the bim promoter through protein-protein interactions with NF-Y bound to the ICB. Furthermore, studies in other systems have demonstrated that $\mathrm{CBP} / \mathrm{p} 300$ can interact with the other regulatory factors, c-Jun, FOXO and Myb, ${ }^{22,33,34}$ which activate bim transcription in neurons. We have shown that $\mathrm{FOXO}$ a binds to two conserved FOXO sites in the bim promoter following NGF withdrawal. In addition, we have demonstrated that FOXO3a interacts with $\mathrm{CBP}$ and p300 in extracts from neuronal cells, in the absence of NGF.

CBP and p300 can act as a 'bridge' to connect sequencespecific transcription factors to the basal transcription machinery ${ }^{32}$ and their large size allows multiple proteins to bind to them simultaneously. It is possible that a multi-protein enhanceosome-like structure ${ }^{35}$ may form on the bim promoter following NGF withdrawal, since we have shown that CBP/ p300 can bind to NF-Y and FOXO3a, and NF-Y is known to recruit the basal transcription machinery and RNA polymerase II to the promoters of CCAAT box-containing genes. ${ }^{25}$ It will be interesting to establish whether this mechanism is also critical in other cell types as the ICB is common to the rat, mouse and human bim genes and NF-Y, FOXO3a and CBP/ p300 are widely expressed. Preliminary experiments using mouse cerebellar granule neurons (CGNs) suggest that the ICB may be important for bim transcription in these cells (Supplementary Figure S4).

In summary, our results support a model (Figure 9) in which NF-Y is bound to the ICB in the presence of NGF and recruits some $\mathrm{CBP} / \mathrm{p} 300$ to the bim promoter. In sympathetic neurons deprived of NGF, FOXO3a translocates from the cytoplasm into the nucleus and binds to the two conserved FOXO sites that flank the ICB. ${ }^{7} \mathrm{CBP} / \mathrm{p} 300$ binding to the bim promoter increases significantly after NGF withdrawal because CBP/ p300 can be recruited by FOXO3a as well as NF-Y. Therefore, following NGF withdrawal, NF-Y and FOXO3a (and potentially other factors such as c-Jun and Myb) recruit CBP/p300 to form a stable multi-protein complex that increases the rate of bim transcription (Figure 9). Such protein-protein interactions would therefore integrate the different signalling pathways that cooperatively activate the bim promoter following survival factor withdrawal.

\section{Materials and Methods}

Plasmid constructs. The bim-LUC reporter consists of a $5.2 \mathrm{~kb}$ fragment, containing the region immediately $5^{\prime}$ to the rat bim initiator codon, sub-cloned into pGL3-basic. ${ }^{7}$ The bim-LUC CCAAT(-) construct was generated using the oligonucleotides 5'-GAGCCCGCGGTGAGCTCGCGCCGGAGCGGG-3' and 5'-CC CGCTCCGGCGCGAGCTCACCGCGGGCTC-3'. The altered bases (underlined) create four point mutations in the ICB. The bim-LUC CCAAT (-) FOXO(dm) 

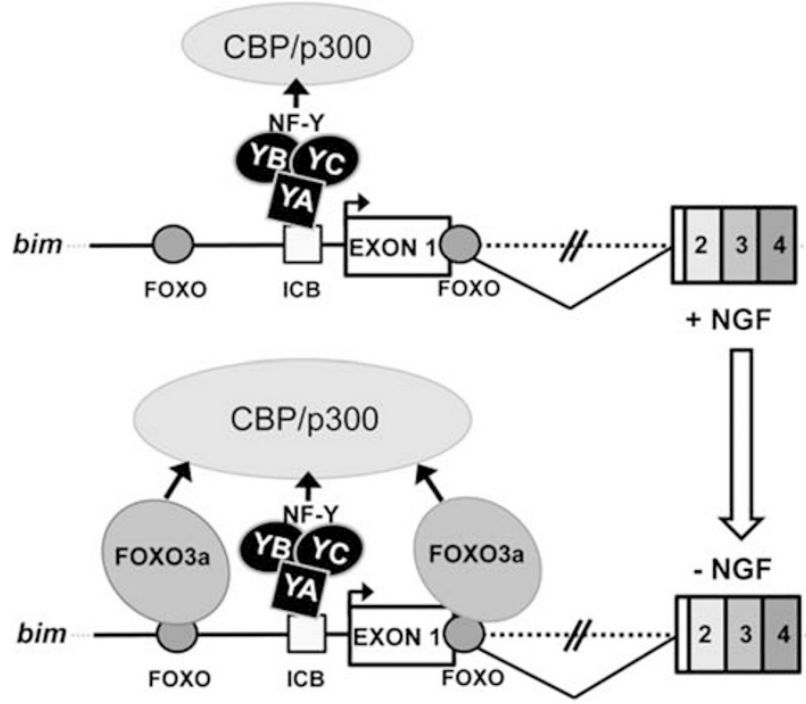

Figure 9 Hypothetical model showing how transcription factors bind to the bim promoter in sympathetic neurons in the presence of NGF and following NGF withdrawal. In the presence of NGF, NF-Y is bound to the ICB and can recruit some $\mathrm{CBP} / \mathrm{p} 300$ to the bim promoter. In sympathetic neurons deprived of NGF, FOXO3a translocates from the cytoplasm into the nucleus and binds to the two conserved FOXO sites in the bim promoter that flank the ICB. CBP/p300 binding to the bim promoter increases significantly after NGF withdrawal because CBP/p300 can interact with FOXO3a as well as NF-Y. Following NGF withdrawal, NF-Y and FOXO3a may recruit $\mathrm{CBP} / \mathrm{p} 300$ to form a stable multi-protein complex that increases the rate of transcription of bim

construct was generated by incorporating point mutations into FOXO site 1 and FOXO site 2 within bim-LUC CCAAT $(-)$ using oligonucleotides described previously. ${ }^{7}$ Mutagenesis was carried out using the QuikChange II XL site-directed mutagenesis kit (Stratagene, Agilent, Santa Clara, CA, USA). YA13 m29 is a dominant negative mutant of the NF-YA subunit ${ }^{15}$ cloned into the expression vector pSG5 (Stratagene). The expression vector for p300 was supplied by Upstate (Millipore, Billerica, MA, USA). It consists of the human p300 cDNA cloned into $\mathrm{pCMV} \beta$ (CMVp300). The expression vector pcDNA3.1 (Invitrogen, Carlsbad, CA, USA), which contains the CMV promoter, was used as an empty vector control. The expression vector for CBP was kindly provided by Professor Tony Kouzarides (The Gurdon Institute, Cambridge, UK). It contains the mouse CBP CDNA cloned into $\mathrm{pRc} / \mathrm{RSV}$ (pRc/RSV-mCBP). The expression vector $\mathrm{pB} J 9 \Omega$, which is also under the control of the RSV promoter, was used as an empty vector control (also supplied by T Kouzarides). The CREB reporter construct PCRE-LUC and the control without CRE sites, pLUC, were supplied by Stratagene. FKH $(\mathrm{DBD})^{7}$ is the DNA-binding domain of FOXO3a cloned into the expression vector pcDNA1 (Invitrogen).

Cell culture. Sympathetic neurons were isolated from the superior cervical ganglia (SCG) of 1-day-old Sprague Dawley rats and cultured as described previously. ${ }^{36}$ Cells were maintained in SCG medium supplemented with 2.5S NGF (Cedarlane, Burlington, Canada) at $50 \mathrm{ng} / \mathrm{ml}$, and fluorodeoxyuridine and uridine (both from Sigma-Aldrich, St Louis, MO, USA), each at $20 \mu \mathrm{M}$. PC6-3 cells, a subline of the PC12 cell line, ${ }^{37}$ were cultured as described previously. ${ }^{19}$ For differentiation, PC6-3 cells were maintained in medium containing $2 \%$ horse serum, $1 \%$ FCS and NGF (Promega, Fitchburg, WI, USA) at $100 \mathrm{ng} / \mathrm{ml}$, for 5-7 days. In NGF withdrawal experiments, cells were rinsed twice with medium (without NGF) and then refed with medium containing an anti-NGF antibody at $100 \mathrm{ng} / \mathrm{ml}$ (Chemicon, Millipore). For experiments with PCRE-LUC and PLUC, sympathetic neurons were refed with + NGF medium containing $500 \mu \mathrm{M}$ CPTcAMP (Sigma-Aldrich).

Cerebellar granule neurons were prepared from 7-day-old mice and maintained in medium containing $25 \mathrm{mM} \mathrm{KCl}$, as described previously. ${ }^{38,39}$ In $\mathrm{KCl}$ deprivation experiments, neurons were washed once and then incubated in serum-free BME supplemented with L-GIn, HEPES, antibiotics and $1 \mu \mathrm{M}$ of the NMDA antagonist (+) MK-801, and $5 \mathrm{mM} \mathrm{KCl} \mathrm{(K5} \mathrm{medium)} \mathrm{to} \mathrm{induce} \mathrm{apoptosis.}$
Microinjection. Sympathetic neurons were cultured in vitro for 5-7 days and then microinjected as described previously. ${ }^{4}$ Approximately 150 cells were injected per coverslip and each injection experiment was repeated at least three times. Plasmids were injected into the nucleus of each cell and over $90 \%$ of cells survived injection.

Dual luciferase assays were carried out on injected cells using the Dual luciferase reporter assay system (Promega). Cells were harvested for luciferase assays at $16 \mathrm{~h}$ following NGF withdrawal.

For antibody coinjection experiments, the Santa Cruz (Santa Cruz, CA, USA) p300 (C-20:Sc-585 X) and CBP (C-20:Sc-583 X) antibodies were diluted in PBS (-) and centrifuged in Microcon YM-3 centrifugal filters (Millipore) to remove sodium azide. Antibodies were injected at a final concentration of $1 \mu \mathrm{g} / \mu \mathrm{l}$ and purified rabbit immunoglobulin in PBS (Jackson ImmunoResearch, West Grove, PA, USA) was used as a control.

In cell survival assays, neurons were injected with the YA13 m29 expression vector or the control empty vector (pSG5) at $200 \mathrm{ng} / \mu \mathrm{l}$, along with $5 \mu \mathrm{g} / \mu \mathrm{l}$ of TRD (70 000 MW; Molecular Probes, Invitrogen, Carlsbad, CA, USA).

Transfection of CGNs. CGNs cultured in 24-well plates were transfected at 5 days in vitro with $0.5 \mu \mathrm{g}$ of pRL-TK together with $1.5 \mu \mathrm{g}$ of either the bim-LUC or bim-LUC CCAAT(-) constructs, using calcium phosphate precipitation as described previously. ${ }^{39}$ After $24 \mathrm{~h}$ the cells were either left untreated (K25) or deprived of $\mathrm{KCl}(\mathrm{K} 5)$. Four hours after deprivation, transfected neurons were harvested for luciferase assays using the Dual luciferase reporter assay system.

Immunocytochemistry. Neurons were injected with the YA13 m29 expression vector or the control empty vector (pSG5) at $20 \mathrm{ng} / \mu \mathrm{l}$ along with $2.5 \mu \mathrm{g} / \mu \mathrm{l}$ of purified gp IgG (Jackson ImmunoResearch) and fixed and stained as described before. ${ }^{7}$ In brief, cells were fixed in $4 \%$ paraformaldehyde, permeabilised in $0.5 \%$ Triton-X-100 and blocked in $50 \%$ goat serum (Sigma-Aldrich). After washing, cells were incubated in a primary antibody to detect NF-YA (Santa Cruz Sc-10779:H-209) or Bim (\# 2819; Cell Signalling, Danvers, MA, USA). Secondary antibodies were a FITC-conjugated anti-rabbit IgG, and a rhodamine anti-gp IgG if neurons were microinjected (both from Jackson ImmunoResearch). Secondary-only controls were carried out to confirm the specificity of primary antibodies and cells were scored in a blinded manner whenever possible. TUNEL analysis was carried out using an in situ cell death detection kit (Roche, Basel, Switzerland). All slides were viewed using a Zeiss Axioplan 2 fluorescence microscope.

Electrophoretic mobility shift assay. EMSA experiments were performed on nuclear lysates from differentiated PC6-3 cells maintained in medium containing NGF or withdrawn from NGF for $16 \mathrm{~h}$, and whole cell lysates from sympathetic neurons maintained in medium containing NGF or withdrawn from NGF for $16 \mathrm{~h}$. Nuclear lysates were prepared from PC6-3 cells and whole cell extracts were prepared from sympathetic neurons as described previously..$^{19,40}$ Double-stranded oligonucleotides with $5^{\prime}$ overhangs were labelled by filling in with Klenow polymerase (Roche) and $\left(\alpha^{-}{ }^{32} \mathrm{P}\right)$ dCTP $(3000 \mathrm{Ci} / \mathrm{mmol}$; PerkinElmer, Wellesley, MA, USA). Oligonucleotide pairs used for EMSA experiments were as follows: bim CCAAT wt 5'-CTAGCCCGCGGTGATTGGGCGCCGGAG-3' and $5^{\prime}$-C TAGCTCCGGCGCCCAATCACCGCGGG-3' and bim CCAAT mut $5^{\prime}$-CTAGCC CGCGGTGAGCTCGCGCGGAG-3' and 5'-CTAGCTCCGGCGCGAGCTCACCGC GGG-3' (the mutated bases of the ICB are underlined). Oligonucleotides containing a CCAAT box from the rat GTP $\mathrm{C1}$ gene were used as a positive control: GTP $\mathrm{C} 1 \mathrm{wt}$ $5^{\prime}$-CTAGGCTCGGCCAATGAGAACGCCT-3' $3^{\prime}$ and $5^{\prime}$-CTAGAGGCGTTCTCATTG GCCCGAGC-3' and GTP C1 mut 5'-CTAGCTCGGGGAGCTGAGAACGCCT-3' and $5^{\prime}$-CTAGAGGCGTTCTCAGCTCCCCGAGC- $3^{\prime} .^{12}$ Binding reactions were set up in a $20 \mu \mathrm{l}$ volume as described previously, ${ }^{12}$ with $5 \mu \mathrm{g}$ of nuclear extract from PC6-3 cells and $10 \mu \mathrm{g}$ of whole cell extract from sympathetic neurons. Supershift experiments were carried out by incubating samples on ice with antibodies $(4 \mu \mathrm{g})$ for $2 \mathrm{~h}$. The Santa Cruz NF-YA (H-209:Sc-10779 X) antibody was used in EMSA experiments along with c-Jun (H-79:Sc-1694 X) or Fra-2 (L-15:Sc-171 X) antibodies as negative controls (Santa Cruz). Samples were incubated with $0.4 \mathrm{ng}$ of ${ }^{32} \mathrm{P}$-labelled oligonucleotide for $15 \mathrm{~min}$ at room temperature and run on a $5 \%$ polyacrylamide gel. After electrophoresis, gels were fixed in $10 \%$ acetic acid $/ 10 \%$ methanol, dried and bands were visualised by exposing the gel to MXB X-ray film (Kodak, Rochester, NY, USA).

Chromatin immunoprecipitation. Differentiated PC6-3 cells $\left(\sim 4 \times 10^{6}\right.$ cells per $9 \mathrm{~cm}$ dish) were either maintained in the presence of NGF, or withdrawn from NGF for $16 \mathrm{~h}$. The cells were fixed in $1 \%$ formaldehyde for $3 \mathrm{~h}$ at room 
temperature and ChIP was performed using a ChIP assay kit from Upstate (Millipore) with some modifications, as described previously. ${ }^{19}$ The following antibodies from Santa Cruz were used for ChIP: NF-YA (H-209:Sc-10779 X), p300 (C-20:Sc-585 X), CBP (C-20:Sc-583 X) and FOXO3a (H-144:Sc-11351 X). Millipore Bim (AB17003) and Santa Cruz MyoD (M-318:Sc-760 X) antibodies were used as negative controls.

ChIP samples were analysed by semi-quantitative PCR. To detect binding of NF-Y to the ICB in the rat bim promoter the following primer pair was used: $5^{\prime}$-CAGGCCAAGTCACTAGGGTAAACAC-3' and 5'-GAATCCGGTGACTGCAAC GACAA $-3^{\prime}$. The same primer pair was used to detect binding of p300 and CBP to this region. The following primer pairs were used to detect binding of FOXO3a to FOXO site 1: $5^{\prime}$-CTAAGTTCCGCTCTGCGAGGT-3' and $5^{\prime}$-TGCAGGCTGCGAC AGGTAGT- $3^{\prime}$, and FOXO3a to FOXO site 2: $5^{\prime}$-GATTCACACCACCTCCGCT- $3^{\prime}$ and $5^{\prime}$-GCCTGTCTTCTATCCATCCC-3'. Samples were analysed between 25 and 30 cycles and the average amount of bim promoter DNA, precipitated by each antibody, was calculated using ImageQuant image analysis software (GE Healthcare, Waukesha, WI, USA).

Co-immunoprecipitation. The co-immunoprecipitation (co-IP) experiments were performed on nuclear lysates from differentiated PC6-3 cells maintained in + NGF medium or withdrawn from NGF for $16 \mathrm{~h}$. A $50 \%$ slurry of protein A/Gagarose (Santa Cruz) was prepared in PBS (-) and added to a 1.5-ml microfuge tube containing $2 \mu \mathrm{g}$ of antibody to immunoprecipitate either FOXO3a (Cell Signaling; \#2497), p300, CBP or NF-Y (NF-Y, p300 and CBP antibodies were the same for co-IP and ChIP), and resuspended in $500 \mu$ l of ice-cold PBS (-). This was also repeated for the non-specific control, purified rabbit immunoglobulin in PBS (Jackson ImmunoResearch). The mixtures were incubated at $4^{\circ} \mathrm{C}$ for $90 \mathrm{~s}$ and the beads were collected by centrifugation at $15700 \times \mathrm{g}$ for $2 \mathrm{~s}$ at $4^{\circ} \mathrm{C}$. The supernatant containing the unbound antibody was removed and the beads were resuspended in $1 \mathrm{ml}$ of non-denaturing lysis buffer ( $1 \% \mathrm{v} / \mathrm{v}$ Triton-X100, $50 \mathrm{mM}$ Tris- $\mathrm{HCl} \mathrm{pH} 7.4$, $300 \mathrm{~mm} \mathrm{NaCl}, 5 \mathrm{~mm}$ EDTA, $0.02 \% \mathrm{v} / \mathrm{v} \mathrm{NaN}$ pH 7.4, $1 \mathrm{~mm}$ PMSF). The tubes were inverted four times to mix and the beads were collected by centrifugation as previously. The beads were then washed in $1 \mathrm{ml}$ of non-denaturing lysis buffer and collected by centrifugation. Around $80 \mu \mathrm{g}$ of nuclear lysate was added to each tube containing specific or control antibody-bound beads. The mixture was incubated at $4{ }^{\circ} \mathrm{C}$ for $2 \mathrm{~h}$ with rotation. The beads were then collected by centrifugation and the supernatant was removed. The beads were resuspended in $1 \mathrm{ml}$ of ice-cold wash buffer, the tubes inverted four times to mix, and the beads were collected by centrifugation as previously. This wash step was repeated three times and the final supernatant was removed to leave the beads in $\sim 15 \mu$ l of wash buffer (containing the immune complexes). The beads were resuspended in $30 \mu$ of SDS gel sample buffer, boiled for $5 \mathrm{~min}$ at $100^{\circ} \mathrm{C}$ and analysed by immunoblotting as described previously. ${ }^{7}$ The NF-YA, FOXO3a, p300 and CBP antibodies used for immunoprecipitation were also used for immunoblots and an ERK $1 / 2$ antibody (Cell Signaling; \# 9102) was used to check protein loading.

To prepare nuclear extracts for co-IP, neuronally differentiated PC6-3 cells were washed twice in ice-cold PBS (-) and then scraped off the dishes in $2 \mathrm{ml}$ of PBS (per $9 \mathrm{~cm}$ dish). Cells were pelleted by centrifugation at $400 \times \mathrm{g}$ for $5 \mathrm{~min}$ at $4{ }^{\circ} \mathrm{C}$ and resuspended in $200 \mu$ l of buffer $\mathrm{A}$ ( $10 \mathrm{~mm}$ Hepes $\mathrm{pH} 7.9,10 \mathrm{mM} \mathrm{KCl}, 0.1 \mathrm{~mm}$ EDTA, $0.1 \mathrm{~mm}$ EGTA, $1 \mathrm{~mm}$ DTT, $0.5 \mathrm{~mm}$ PMSF) before incubation on ice for $15 \mathrm{~min}$. NP40 $(10 \%)$ was added to each lysate (to a final concentration of $1 \%$ ) and the samples were vortexed for $15 \mathrm{~s}$ before incubation for $15 \mathrm{~min}$ at $4^{\circ} \mathrm{C}$. The lysates were pelleted by centrifugation at $13000 \times g$ for $30 \mathrm{~s}$, resuspended in $200 \mu \mathrm{l}$ of ice-cold buffer C (20 mm Hepes pH 7.9, 400 mm NaCl, 1 mm EDTA, 1 mm EGTA, 1 mm DTT, $1 \mathrm{mM} \mathrm{PMSF}, 25 \% \mathrm{v} / \mathrm{v}$ glycerol) and incubated at $4^{\circ} \mathrm{C}$ with shaking. After $1 \mathrm{~h}$, lysates were vortexed for $30 \mathrm{~s}$ and pelleted by centrifugation for $10 \mathrm{~min}$ at $15700 \times \mathrm{g}$ at $4^{\circ} \mathrm{C}$. The supernatant was removed and this was the nuclear extract.

Statistical analysis. In each set of experiments, data are normalised to a control sample (for example, bim-LUC + NGF is set to one). For microinjection, the relative induction of a DNA construct is calculated by dividing the normalised luciferase activity in the absence of NGF by the normalised luciferase activity in the presence of NGF. All data are presented as the mean \pm S.E. of multiple experiments.

The statistical significance of differences between means was evaluated by performing an unpaired Student's t-test (for two-tailed distributions), followed by a Bonferroni correction. To compare normalised data with the control sample, which has no error associated to it (for example, when comparing data to bim-LUC + NGF, which is set to one), the $\log 10$ values of the data were taken and a one sample $t$-test was used (for two-tailed distributions). Statistical significance is presented as $P$-values in the Figures.

\section{Conflict of interest}

The authors declare no conflict of interest.

Acknowledgements. We thank Tony Kouzarides for providing the expression vector for CBP, Becky Randall for advice on EMSA assays, and Francesca Menghi and Mike Hubank for critical reading of the manuscript. This work was supported by The Wellcome Trust (Senior Research Fellowship in Basic Biomedical Science 057700 to $\mathrm{JH}$ ). RM is supported by the Associazione Italiana Ricerca Cancro (AIRC). SD and IL are supported by the Centre National de la Recherche Scientifique (CNSR) and the Institut National de la Santé et de la Recherche Médicale (INSERM).

1. Chen L, Willis SN, Wei A, Smith BJ, Fletcher Jl, Hinds MG et al. Differential targeting of prosurvival $\mathrm{Bcl}-2$ proteins by their $\mathrm{BH} 3-o n l y ~ l i g a n d s$ allows complementary apoptotic function. Mol Cell 2005; 17: 393-403.

2. Chipuk JE, Moldoveanu T, Llambi F, Parsons MJ, Green DR. The BCL-2 family reunion. Mol Cell 2010; 37: 299-310.

3. Deshmukh M, Johnson Jr EM. Programmed cell death in neurons: focus on the pathway of nerve growth factor deprivation-induced death of sympathetic neurons. Mol Pharmacol 1997; 51: 897-906.

4. Whitfield J, Neame SJ, Paquet L, Bernard O, Ham J. Dominant-negative c-Jun promotes neuronal survival by reducing BIM expression and inhibiting mitochondrial cytochrome $\mathrm{C}$ release. Neuron 2001; 29: 629-643.

5. Coultas L, Terzano S, Thomas T, Voss A, Reid K, Stanley EG et al. Hrk/DP5 contributes to the apoptosis of select neuronal populations but is dispensable for haematopoietic cell apoptosis. J Cell Sci 2007; 120: 2044-2052.

6. Besirli CG, Wagner EF, Johnson Jr EM. The limited role of NH2-terminal c-Jun phosphorylation in neuronal apoptosis: identification of the nuclear pore complex as a potential target of the JNK pathway. J Cell Biol 2005; 170: 401-411.

7. Gilley J, Coffer PJ, Ham J. FOXO transcription factors directly activate bim gene expression and promote apoptosis in sympathetic neurons. J Cell Biol 2003; 162: 613-622.

8. Biswas SC, Liu DX, Greene LA. Bim is a direct target of a neuronal E2F-dependent apoptotic pathway. J Neurosci 2005; 25: 8349-8358.

9. Juven-Gershon T, Kadonaga JT. Regulation of gene expression via the core promoter and the basal transcriptional machinery. Dev Biol 2010; 339: 225-229.

10. Lenhard B, Sandelin A, Mendoza L, Engstrom P, Jareborg N, Wasserman WW. Identification of conserved regulatory elements by comparative genome analysis. J Biol 2003; 2: 13.

11. Mantovani R. A survey of 178 NF-Y binding CCAAT boxes. Nucleic Acids Res 1998; 26 : 1135-1143.

12. Kapatos G, Stegenga SL, Hirayama K. Identification and characterization of basal and cyclic AMP response elements in the promoter of the rat GTP cyclohydrolase I gene. J Biol Chem 2000; 275: 5947-5957.

13. Manni I, Caretti G, Artuso S, Gurtner A, Emiliozzi V, Sacchi A et al. Posttranslational regulation of NF-YA modulates NF-Y transcriptional activity. Mol Biol Cell 2008; 19 : 5203-5213.

14. Gilley J, Ham J. Evidence for increased complexity in the regulation of bim expression in sympathetic neurons: involvement of novel transcriptional and translational mechanisms. DNA Cell Biol 2005; 24: 563-573.

15. Mantovani R, Li XY, Pessara U, Hooft van Huisjduijnen R, Benoist C, Mathis D. Dominant negative analogs of NF-YA. J Biol Chem 1994; 269: 20340-20346.

16. Kasper LH, Fukuyama T, Biesen MA, Boussouar F, Tong C, de Pauw A et al. Conditional knockout mice reveal distinct functions for the global transcriptional coactivators $\mathrm{CBP}$ and p300 in T-cell development. Mol Cell Biol 2006; 26: 789-809.

17. Arias J, Alberts AS, Brindle $P$, Claret FX, Smeal T, Karin $M$ et al. Activation of CAMP and mitogen responsive genes relies on a common nuclear factor. Nature 1994; 370: 226-229.

18. Estus S, Zaks WJ, Freeman RS, Gruda M, Bravo R, Johnson Jr EM. Altered gene expression in neurons during programmed cell death: identification of $\mathrm{c}$-jun as necessary for neuronal apoptosis. J Cell Biol 1994; 127: 1717-1727.

19. Towers E, Gilley J, Randall R, Hughes R, Kristiansen M, Ham J. The proapoptotic dp5 gene is a direct target of the MLK-JNK-c-Jun pathway in sympathetic neurons. Nucleic Acids Res 2009; 37: 3044-3060.

20. Yao TP, Oh SP, Fuchs M, Zhou ND, Ch'ng LE, Newsome D et al. Gene dosage-dependent embryonic development and proliferation defects in mice lacking the transcriptional integrator p300. Cell 1998; 93: 361-372.

21. Tanaka Y, Naruse I, Hongo T, Xu M-J, Nakahata T, Maekawa T et al. Extensive brain hemorrhage and embryonic lethality in a mouse null mutant of CREB-binding protein. Mech Dev 2000; 95: 133-145. 
22. Mahmud DL, G-Amlak M, Deb DK, Platanias LC, Uddin S, Wickrema A. Phosphorylation of forkhead transcription factors by erythropoietin and stem cell factor prevents acetylation and their interaction with coactivator p300 in erythroid progenitor cells. Oncogene 2002; 21: 1556-1562.

23. Ham J, Babij C, Whitfield J, Pfarr CM, Lallemand D, Yaniv M et al. A C-Jun dominant negative mutant protects sympathetic neurons against programmed cell death. Neuron 1995; 14: 927-939.

24. Kristiansen M, Hughes R, Patel P, Jacques TS, Clark AR, Ham J. Mkp1 is a c-Jun target gene that antagonises JNK-dependent apoptosis in sympathetic neurons. J Neurosci 2010; 30: 10820-10832

25. Kabe $Y$, Yamada J, Uga H, Yamaguchi $Y$, Wada T, Handa H. NF-Y is essential for the recruitment of RNA polymerase II and inducible transcription of several CCAAT boxcontaining genes. Mol Cell Biol 2005; 25: 512-522.

26. Di Agostino S, Strano S, Emiliozzi V, Zerbini V, Mottolese M, Sacchi A et al. Gain of function of mutant $p 53$ : The mutant $p 53 / N F-Y$ protein complex reveals an aberrant transcriptional mechanism of cell cycle regulation. Cancer Cell 2006; 10: 191-202.

27. Benatti $P$, Basile V, Merico D, Fantoni LI, Tagliafico E, Imbriano C. A balance between NF-Y and p53 governs the pro- and anti-apoptotic transcriptional response. Nucleic Acids Res 2008; 36: 1415-1428.

28. Putcha GV, Johnson Jr EM. Men are but worms: neuronal cell death in $\mathrm{C}$ elegans and vertebrates. Cell Death Differ 2004; 11: 38-48.

29. Ham J, Towers E, Gilley J, Terzano S, Randall R. BH3-only proteins: key regulators of neuronal apoptosis. Cell Death Differ 2005; 12: 1015-1020.

30. Wyttenbach A, Tolkovsky AM. The BH3-only protein Puma is both necessary and sufficient for neuronal apoptosis induced by DNA damage in sympathetic neurons. J Neurochem 2006; 96: 1213-1226.
31. Salsi V, Caretti G, Wasner M, Reinhard W, Haugwitz U, Engeland K et al. Interactions between p300 and multiple NF-Y trimers govern cyclin B2 promoter function. J Biol Chem 2003; 278: 6642-6650.

32. Chan HM, La Thangue NB. p300/CBP proteins: HATs for transcriptional bridges and scaffolds. J Cell Sci 2001; 114: 2363-2373.

33. Lee JS, See RH, Deng T, Shi Y. Adenovirus E1A downregulates cJun- and JunB-mediated transcription by targeting their coactivator p300. Mol Cell Biol 1996; 16: 4312-4326.

34. Bessa M, Saville MK, Watson RJ. Inhibition of cyclin A/Cdk2 phosphorylation impairs B-Myb transactivation function without affecting interactions with DNA or the CBP coactivator. Oncogene 2001; 20: 3376-3386.

35. Merika M, Williams AJ, Chen G, Collins T, Thanos D. Recruitment of CBP/p300 by the IFN beta enhanceosome is required for synergistic activation of transcription. Mol Cell 1998; 1 : 277-287.

36. Whitfield J, Neame SJ, Ham J. Methods for culturing primary sympathetic neurons and for determining neuronal viability. Methods Mol Biol 2004; 282: 157-168.

37. Pittman RN, Wang S, DiBenedetto AJ, Mills JC. A system for characterizing cellular and molecular events in programmed neuronal cell death. J Neurosci 1993; 13: 3669-3680.

38. Desagher S, Severac D, Lipkin A, Bernis C, Ritchie W, Le Digarcher A et al. Genes regulated in neurons undergoing transcription-dependent apoptosis belong to signaling pathways rather than the apoptotic machinery. J Biol Chem 2005; 280: 5693-5702.

39. Lassot I, Robbins I, Kristiansen M, Rahmeh R, Jaudon F, Magiera MM et al. Trim17, a novel E3 ubiquitin-ligase, initiates neuronal apoptosis. Cell Death Differ 2010; 17: 1928-1941. Epub 2010 Jun 18.

40. Wong C, Rougier-Chapman EM, Frederick JP, Datto MB, Liberati NT, Jian-Ming L et al Smad3-Smad4 and AP-1 complexes synergize in transcriptional activation of the c-Jun promoter by transforming growth factor. Mol Cell Biol 1999; 19: 1821-1830.

\section{Supplementary Information accompanies the paper on Cell Death and Differentiation website (http://www.nature.com/cdd)}

